\title{
The role of cognate English-Kurdish words in teaching English
}

\section{Suleyman Kasap}

ELT Department, Van Yüzüncü Yıl University, Turkey.

Accepted 17 September, 2018

\begin{abstract}
Cognate words are considered to be one of the influential teaching tools in applied linguistics and the benefits of using them have been proved by several pieces of research so far. However, in literature, we can see nearly no studies related to the cognate words between English language and Kurdish language. In this study, in order to show the effect of cognate structures in teaching a foreign language, we applied an English vocabulary test including 25 Kurdish-English cognate words and 25 non-cognate words. The study group consisting of two control groups (one Turkish monolingual and one Turkish-Kurdish bilingual group) and one experimental group made up of Kurdish-Turkish bilinguals. The meanings of the words were given to all three groups via slides on smart boards on classroom before the test. However, the study group was given instruction with regards to the cognate structures between English and Kurdish. After application of the test, the results showed that the study group could remember the most of the cognate words, in contrast to the control groups. Accordingly, the results suggest that there is a positive correlation between being aware of cognates and recalling words; thereby confirming the idea that teaching through cognate Kurdish-English cognate words facilitates teaching vocabulary.
\end{abstract}

Keywords: Foreign Language, vocabulary acquisition, teaching language through cognate words.

E-mail: kasap_hakan@hotmail.com.

\section{INTRODUCTION}

From the perspective of the world-renowned linguist Ferdinad de Saussure, languageologists try to teach the language and its structure in different ways. Relative linguistic communities from the same cognate are considered to be the same primitive syllabic. Because the history of many languages is short, the exact cognate of a few languages is known (David, 2007). These tongues, which are related to one another, naturally bear many similarities. Similarity can be used as a language teaching tool (Jessner, 1999; Herdina and Jessner, 2000; Cenoz, 2001; De Angelis and Larry, 2001; Proctor et al., 2006; Comesaña et al., 2013). A kinship between languages should be mentioned in order for Cognates to have two words that share similar meanings, spelling and pronunciation. For example, very few cognate words can be found between English and Chinese, but about 30 to $40 \%$ of English words are similar to Spanish words (Wages, 2014). Cognates words for Spanish-speaking individuals are a clear bridge to English language learning. As one might expect, in the first and second language acquisition studies, researchers seem to be benefiting from giving awareness training to the students about the cognates. Radical awareness training can be defined as the ability to use words with similar characteristics on the main axis as a means to recognize a second language. Even in English teaching, this training is given to young pre-school children as well as to young adults in Spain. Students are trained in cognate according to class levels, and more complex cognates are classified according to student levels. Teaching words with similar origins through cognate education is extremely useful and provides learners with faster English learning (Wages, 2014).

As a result of the increasing emphasis on foreign language learning in many bilingual European Union countries, applied linguistics is now trying to make language acquisition practical with different approaches to language teaching. Accordingly, the closeness of the 
previously learned languages to the languages to be taught is no longer ignored. Turkey is seen as one of the worst countries at teaching foreign languages according to Political, Economic and Social Research Foundation (SETA)'s analysis (2014). It is stated that foreign language education is taken until high school or even university graduation, but that the foreign language can not be learned or taught despite these improvements and politics. In addition, the English Proficiency Index (EPI) shows that Turkey's EPI score in the proficiency is very low with 47.80. According to EPA data, Turkey's rank at teaching English is 47 out of 63 countries (2014). These results naturally show that Turkey needs different and more efficient methods to teach English language.

Is it possible to use English or other foreign language teaching in the languages that are already known by individuals in our country, which is defined as a multicultural, very mother tongue and a very faithful society? This question also reveals the purpose of this study. The use of previously acquired languages in English teaching is one of the aims of this work. More specifically, we tried to bring a different understanding of teaching English vocabulary using the similarity of words between Kurdish and English. The similarity between these two languages belonging to the Indo-European family of languages was the basis of this study and this study was undertaken to ascertain whether there is any influence of the language acquired in the teaching of English words through structural relations between cognate words.

\section{Teaching language through cognate words}

One of the most widely accepted practices in foreign language teaching is the understanding that other languages should be excluded and that only the target language is the language allowed in the class. On the contrary, Jessner (1999) first suggests that the language(s) most closely related to the language (s) to be taught among the previous languages (L1, L2 or L3) The introduction of cognates is seen and recommended as a useful tool in finding the meaning of new English words (Jessner and Carlo, 2004).

Cognates have been used in a large number of studies examining if language itself can be a tool for bilinguals to access the words of the target language or not; whether the words in the target language or in the language relevant to the context are considered for recognition during reading (Scarborough et al., 1984; Soares and Grosjean, 1984). Rodríguez (2001) is one of the researchers who suggest that they can be taught through meaningful reading in English and based on the knowledge and literacy of students in their native language. The same researcher also says that teachers can analyse L2 and use L1/L2 cognates words to read L2 texts and teach students that language faster. Dressler conducted a research among fifth-grade Spanish- speaking students (2005), by using cognate relations as a literacy strategy, and the results of the study showed that the participants being aware of cognate relations were more successful than those in control group. Furthermore, Dressler suggested that there is a phonologically differentiation between the groups in perception of L1/L2 cognate words, and that the cognate words are pronounced more pronounced and more accurately by the group with more awareness. CaplanCarbin (2006) proposed a systematic teaching of historical voice and vocabulary similarity between English and German to expand the vocabulary of the English language more quickly and easily using English words. Later, the researcher who worked on this recommendation emphasized the importance of language teaching through cognate words by demonstrating better test results than the control group of the group considering the structural relationship and similarity between the two languages. The findings of this study should be considered as important pedagogical values.

Ringbom (2001) refers to the existence of three levels in a similar syllabic word transfer and calls them general level, item level and system level. The general level of transfer refers to the general perception of similarities between languages by students. These levels encompass the common alphabet and sound units, from grammatical structures to cognate structures. The general similarities between Ringbom languages suggest that students have a general facilitating influence on learning decision and in particular understanding processes. As learners become aware of cognates and learn other languages, they significantly increase the likelihood of learning the language(s) they know (Odlin, 1989). The ability to benefit from radical structures depends on the student's awareness of the similarities between the two items on the back and the systems. Starting from the common alphabet, this awareness encompasses other word similarities, grammatical categories (status, sex, word classes), and similar phonetic structures. This, in turn, makes it inevitable that the similarities between languages will be given to the students concerned. Oller et al. (2007) emphasized that while vocabulary is taught to Spanish students, Spanish and English languages should be used in close proximity to each other. These languages, which contain more than 1500 words, are much better taught by this system. So it can be claimed that bilingual learners are more likely to recognize cognates than monolingual learners. It also underlines that understanding the words and keeping them in mind is a crucial factor through similarity relations according to psychologists working on human consciousness (Rips, 1994).

\section{METHODOLOGY}

In order to test whether the structural relations between English and Kurdish cognate words can facilitate English 
vocabulary learning and to see the effect of cognate word, the research was conducted in a high school, affiliated to the Ministry of National Education in Van province. This study was conducted with 96 high school students. Research Methods in Education (Cohen et al., 2007; Kim, 2015) suggests that if general conclusions are made about the school population as a whole, the sample size needs to be at least 30 , so the size sample of the study can be regarded as adequate. 50 words, 25 of which were Kurdish-English, were asked to all participants as the pre-test and post-test. The results were analysed by using SPSS data analysis.

\section{Participants}

For the study 96 participants (45 females and 51 males) were chosen and the mean age of the sample was 16.8 . Participants were divided into three groups consisting 32 people (one study group and two control groups). The study group was composed of learners who speak Turkish and Kurdish (Bilinguals) and a presentation was made about the possible structural similarities between Kurdish and English words before the post-test. The first control group was selected only from the students who speak Turkish (monolinguals) and the second control group was selected from the students who knew both Turkish and Kurdish (bilinguals). The English level of the participants were nearly same since they got similar English test results in TEOG examination applied by the Minister of Education in Turkey. They were able to answer between 14 and 16 out of 20 questions in TEOG English test, which shows that they have at least elementary level in English. The fact that the English levels of the participants were close to each other was also expressed by their English language teachers.

\section{Procedure}

In this study, a test consisting of 50 words, containing 25 English-Kurdish words, was used. By takin the participants' English proficiency into account, 25 words were selected from The Preliminary and Preliminary for Schools Vocabulary List (Cambridge English, 2012). The test consisted in three parts. In the first part participants were asked to write Turkish meaning of 20 words that were given in English; in the second part, they were asked to match 15 English words with their Turkish equivalent; and finally in multiple-choice part, they were asked to find the English equivalent of the 15 Turkish words. The test was applied as pre-test to all participants. The test took about 20 minutes and after the test the meaning of words given to students by means of slides on the smart board in the classroom to the three groups. However the study group was given an instruction about cognate words between English and Kurdish so that they could realize 25 words were cognate. Due to storage decay, an average person loses $50 \%$ of the memorized information after 20 minutes and $70 \%$ of the information after 24 hours (Ebbinghaus, 1885/1964). The forgetting curve hypothesizes the decline of memory retention in time. This curve shows how information is lost over time when there is no attempt to retain it. Since we want to see whether the participants are aware of the cognate words, the post-test was applied 5 weeks later, which made it nearly impossible for the participants to recollect the words unless the they can see the similarities between the English and Kurdish words (the same vocabulary test applied to the study group and control groups) and the results were analysed by means of SPPS data analysis.

\section{RESULTS}

The data collected from the participants were analysed by means of SPSS in order to see whether there is a difference between being aware of cognate words between English and Kurdish language or not.

Table 1 demonstrates that the number of the female and male participants are equal $(\mathrm{N}=16)$ and their mean points are close to each other; however, there is no statistical difference $(p<0)$ between gender when the pre-tests scores are taken into consideration.

As can be seen in Table 2, the number of the female ( $N$ $=14)$ and male $(\mathrm{N}=18)$ participants are not equal (and their mean points are close to each other; accordingly, there is no statistical difference $(p<0)$ between gender.

As seen in Table 3, there is a slight difference between the pre-test $(\mathrm{M}=20.28)$ and post-test (22.44) and the std. deviation for the tests is about 2 points. To determine whether this difference is statistically meaningful we applied Paired Sample Correlation analysis. The analysis demonstrates that the difference between the pre-test and post-test is meaningful $(\mathrm{P}<0)$.

The study control group given an awareness of cognate words between Kurdish and Turkish language could remember statistically important number of vocabulary, accordingly Table 4 shows a meaningful difference between pre-test and post-test results $(P<0)$.

In Table 4, we can clearly see the similarity between orthographic similarities between Kurdish words and English words (such as Run - revan; Novelty - Nuyîtî; Warm -Germ; Right - Rast etc.) naturally recollecting English words through Kurdish is much easier than learning them through Turkish (such as Run- Kosmak ; Novelty-Yenilik ; Warm-sicak; Right-Dogru , etc.).

\section{DISCUSSION, CONCLUSIONS RECOMMENDATIONS}

Vocabulary knowledge is an important component of a 
Table 1. Gender as variable in bilingual control group.

\begin{tabular}{lllccccc}
\hline Group & Gender & N & Mean & Std. Deviation & t & df & Sig. (2-tailed) \\
\hline \multirow{2}{*}{ Control bilingual } & Pre-test (Female) & 16 & 22.56 & 2.421 & .292 & 30 & .772 \\
& Post-test (Male) & 16 & 22.31 & 2.414 & .292 & 30.000 & .772 \\
\hline
\end{tabular}

Table 2. The paired samples correlations of control monolingual group.

\begin{tabular}{llllcccc}
\hline Group & Gender & $\mathbf{N}$ & Mean & Std. Deviation & $\mathbf{t}$ & df & Sig. (2-tailed) \\
\hline \multirow{2}{*}{ Control monolingual } & Female & 14 & 21.29 & 2.164 & .531 & 30 & .600 \\
& Male & 18 & 20.72 & 3.478 & .562 & 28.802 & .579 \\
\hline
\end{tabular}

Table 3. The paired samples statistics of control bilingual group

\begin{tabular}{llllcc}
\hline Group & & Mean & N & Std. Deviation & Sig. (2-tailed) \\
\hline \multirow{2}{*}{ Pair 1 } & Control bilingual pre test & 20.28 & 32 & 2.067 & .004 \\
& Control bilingual post test & 22.44 & 32 & 2.382 & .004 \\
\hline
\end{tabular}

Table 4. T-Test paired samples statistics of study group.

\begin{tabular}{llllccc}
\hline Tests & & Mean & $\mathbf{N}$ & $\mathbf{t}$ & df & Sig. (2-tailed) \\
\hline \multirow{2}{*}{ Pair 1} & Study group pre-test & 20.28 & 32 & \multirow{2}{*}{16.425} & \multirow{2}{*}{31} & .000 \\
& Study group post-test & 33.16 & 32 & & & \\
\hline
\end{tabular}

language development program for students who are learning English (Nation, 2001). Cognate recognition can be a useful shortcut through the large number of words that English learners must acquire to read and write well in English.

The English vocabulary pre-test and post-test results showed that the similarities and closeness between English and Kurdish languages had a positive effect on the learning and remembering vocabulary performance of the participants. The differences between the study group and the other two control groups were determined by this study, which demonstrates that those having awareness could remember most of the words in the post test, whereas the other two groups could not show a meaningful performance in the test.

Cognate words suggest that structural similarities between languages are an important contributor to learning words and structures permanently. It is clear that there is a significant correlation between awareness of cognate Kurdish-English words and remembering. Based on this study, we can say that if Kurdish English learners are taught the vocabulary by taking the cognate KurdishEnglish words into account, they might be more advantageous in learning vocabulary. In similar studies, the use of relations between languages that are close to each other has been considered as an informational resource ready for learning a new language (Moll et al.,
1992). However, one of the most important consequences of our work is that Kurdish bilinguals may not take advantage of this important opportunity, if they have not been trained in awareness about similarity between Kurdish and English. Similar results from other researchers also showed that the bilingual pupils have not even noticed very obvious similarities despite the advantages of having cognate words (August et al., 2005). It shows us that we need to give education about cognate words and structures in order to recognize the similarities between languages

We see some words given in Table 5 in the three languages and the similarity between Kurdish and English languages is noteworthy. A Kurdish-speaking individual might be able to learn these words more permanently and comfortably as long as being aware of the cognate words in Kurdish and English. Another study on cognate words strongly supports this idea. After a group of students with weak vocabulary were trained to be cognitive flexibility and similarities between languages, the success in word tests increased significantly (Cartwright et al., 2008). This study has shown similar results to the previous studies, which revealed the importance of using structural similarities in English education.

It is clear that a different perspective is needed for language teaching in Turkey, which ranks $62^{\text {nd }}$ in English 
Table 5. Comparing Kurdish-English cognates with Turkish.

\begin{tabular}{lll}
\hline Ingilizce & Kürtçe & Türkçe \\
\hline Remain & Mayîn & Kalmak \\
Right & Rast & Dogru \\
River & Rubar & Nehir \\
Run & Revan & Kosmak \\
Warm & Germ & llik \\
Novelty & Nuyîtî & Yenilik \\
\hline
\end{tabular}

proficiency test applied by EF EPI (2017) and that is Europe's worst performance. Depending on the results of this research, cognate studies can be used in countries where Kurdish is spoken as mother tongue. As our study shows, Kurdish and English show structural similarities because they belong to the same family group of languages, and this structural similarity can be used as an advantage in regions where Kurdish is widely spoken. Also, our study, which focuses on only a group of cognate words -which is also a limitation for this studysuggests that areas such as similarities between grammatical structures should be studied and all cognate Kurdish-English vocabulary can be studied by a systematic research.

\section{REFERENCES}

August, D., Carlo, M., Dressler, C., and Snow, C. (2005). The critical role of vocabulary development for English language learners. Learning Disabilities Research \& Practice, 20(1): 50-57.

Cambridge English (2012). Vocabulary List Cambridge English: Preliminary Cambridge English: Preliminary for Schools. https://www.cambridgeenglish.org/images/84669-pet-vocabularylist.pdf.

Proctor, C. P., August, D., Carlo, M. S., and Snow, C. (2006). The intriguing role of Spanish language vocabulary knowledge in predicting English reading comprehension. Journal of Educational Psychology, 98(1): 159-169.

Cartwright, K., Hodgkiss, M., and Isaac, M. (2008). Graphophonological-semantic flexibility: Contributions to skills reading across the lifespan. In K. Cartwright (Ed.) Literary processes: Cognitive flexibility in learning and teaching. New York, NY: Guilford Press.

Cenoz, J. (2001). The effect of linguistic distance, L2 status and age on cross-linguistic influence in third language acquisition. In J. Cenoz, B. Hufeisen and $U$. Jessner (eds) Cross-linguistic Influence in Third Language Acquisition: Psycholinguistic Perspectives. Clevedon: Multilingual Matters. pp: 8-20.

Comesaña, M., Ferré, P. Sáchez-Casas, R., Fraga, I. Soares, A. P., Rauber, A., and Romero, J. (2013). The contribution of phonology to visual cognate word recognition: Is it modulated by second language exposure? 9th Symposium of Bilingualism, Singapore. www.psycnet.apa.org/journals/xlm/41/3/614.

De Angelis, G., and Larry, S. (2001). Interlanguage transfer and competing linguistic systems in the multilingual mind. In Cenoz, Jasone, B. Hufeisen and Ulrike Jessner (eds.), Cross-linguistic influence in third language acquisition: Psycholinguistic perspectives, 42-58. Clevedon: Multilingual Matters.
Ebbinghaus, H. (1885). Memory: A contribution to experimental psychology. New York: Dover http://psy.ed.asu.edu/ classics/Ebbinghaus/index.htm.

EF English Proficiency Index (EPI) (2017). http://www.ef.com.tr/epi/.

Herdina, P., and Jessner, U. (2000). The dynamics of third language acquisition. In Cenoz, Jasone and Ulriche Jessner (eds.), English in Europe: The acquisition of a third language. Bilingual education and bilingualism, 84-98. Clevedon, England: Multilingual Matters.

Jessner, U. (1999). Metalinguistic awareness in multilinguals: cognitive aspects of third language learning. Language Awareness, 8: 201-209.

Kim, T. K. (2015). T test as a parametric statistic. Korean J Anesthesiol, 68:540-546.

Moll, L., Amanti, C., Neff, D., and González, N. (1992). Funds of knowledge for teaching: A qualitative approach to developing strategic connections between homes and classrooms. Theory into Practice, 31(2): 132-141.

Nation, I. S. P. (2001). Learning vocabulary in another language. Cambridge, UK: Cambridge University Press.

Odlin, T. (1989). Language Transfer. Cross-linguistic Influence in Language Learning. Cambridge: Cambridge University Press.

Oller, K., Pearson, B., and Cobo-Lewis, A. (2007). Profile effect in early bilingual language and literacy. Applied Psycholinguistics, 28: 191230.

Ringbom, H. (2001) Lexical transfer in L3-production. In J. Cenoz, B. Hufeisen and U. Jessner (eds) Cross-linguistic Influence in Third Language Acquisition: Psycho- linguistic Perspectives. Clevedon: Multilingual Matters. pp: 59-68.

Rips, L. (1994). Deduction and its cognitive basis. In R. Sternberg (Ed.) Thinking and problem solving. San Diego, CA: Academic Press.

Siyaset, Ekonomi ve Toplum Araştırmaları Vakfı, SETA. (2014). www.setav.org/.

Scarborough, D. L., Gerard, L., and Cortese, C. (1984). Independence of lexical access in bilingual word recognition. Journal of Verbal Learning and Verbal Behavior, 23: 84-99.

Soares, C., and Grosjean, F. (1984). Bilinguals in a monolingual and a bilingual speech mode: The effect on lexical access. Memory and Cognition, 12: 380-386.

Wages, M. (2014). Engaging the Hispanic Learner: Ten Strategies for Using Culture to Increase Achievement. Rowman \& Littlefield Publishers. https://books.google.com.tr/books.

Citation : Kasap, S. (2018). The role of cognate English-Kurdish words in teaching English. African Educational Research Journal, 6(4): 213-217. 